3

4

5

6

7

8

9

\title{
Utilization of centrate for the production of the marine microalgae
}

\section{Nannochloropsis gaditana}

\author{
C. Sepúlveda ${ }^{1}$, F.G. Acién² ${ }^{2}$ C. Gómez ${ }^{2}$, N. Jiménez-Ruíz², C. Riquelme ${ }^{1}$ E. Molina- \\ Grima $^{2}$ \\ ${ }^{1}$ Department of Applied Microbiology, University of Antofagasta, Chile \\ ${ }^{2}$ Department of Chemical Engineering, University of Almería, 04120 Almería, Spain. \\ Author for correspondence: F. Gabriel Acién Fernández \\ Department of Chemical Engineering, University of Almería \\ Carretera Sacramento s/n, E04120, Almería, Spain \\ Telephone: +34 950015443; Fax: +34 950015484; e-mail: facien@ual.es
}

KEYWORDS: microalgae, wastewater, centrate, nutrient limitation, productivity, biochemical composition 


\section{Abstract}

In this paper, the production of the microalga Nannochloropsis gaditana using centrate from the anaerobic digestion of treated urban wastewater is studied. For this, semicontinuous cultures were performed indoors at laboratory scale, under controlled conditions, supplying seawater with different centrate percentages from a real wastewater treatment plant as the culture medium. It was demonstrated that $N$. gaditana can be produced using solely centrate as the nutrient source but only at percentages below $50 \%$. Above this level, inhibition is caused by an excess of ammonia, thus reducing productivity. In the $30-50 \%$ centrate range, biomass productivity was $0.4 \mathrm{~g} \cdot \mathrm{l}^{-1} \cdot \mathrm{day}^{-1}$, equal to that measured when using Algal culture medium. Moreover, the biochemical composition of the biomass was also equal to that measured when using Algal culture medium, with the protein content in the $30-40 \%$ d.wt. range; whereas the lipid content ranged from 20 to $25 \%$ d.wt. Under these conditions, phosphorus depuration from the culture medium was in the $80-90 \%$ range while nitrogen depuration was only between 20 and $40 \%$, indicating an excess of nitrogen in the centrate with respect to phosphorus. In spite of this phosphorus limitation, in the optimal centrate range $(30-50 \%$ in the culture medium), the cells performed under optimal conditions, removing up to $35 \mathrm{mg}_{\mathrm{N}} \cdot \mathrm{l}^{-1} \cdot \mathrm{day}^{-1}$ and $5.7 \mathrm{mg}_{\mathrm{P}} \cdot \mathrm{l}^{-1} \cdot \mathrm{day}^{-1}$, with quantum yield values measuring $1.0-1.3 \mathrm{~g} \cdot \mathrm{E}^{-1}$. By supplying additional phosphorus, it was possible to enhance productivity and increase nitrate and phosphorus depuration to over $80 \%$. The use of centrate is confirmed as a useful method for reducing microalgae production costs while also increasing process sustainability, especially when using biomass for bioenergy applications. 


\section{Introduction}

Rising oil prices and global warming, associated with the burning of fossil fuels, has prompted a search for renewable, clean and carbon-neutral biofuels. In this scenario, microalgae have been proposed as a third-generation biofuel source given their high potential energy yield per hectare (Chisti, 2007; Mata et al., 2010). For this reason, considerable effort has been made recently to develop technologies for producing biofuels such as bio-diesel, bio-ethanol, bio-methane and bio-hydrogen from microalgae biomass (Rosenberg et al., 2008; Schenk et al., 2008). However, the process has not yet been exploited industrially as the high cost of microalgae biomass production is still too great to compete in the energy field, especially given the limited availability and cost of nutrients (Acién et al., 2012). When using clean water and artificial fertilizers, algae production costs are still very high, more than $5 € / \mathrm{kg}$ of dry mass (Molina-Grima et al., 2003; Norsker et al., 2011; Acién et al., 2012).

Nitrogen and phosphorus, in addition to $\mathrm{CO}_{2}$, are the main nutrients required for microalgae production. Approximately $5 \mathrm{t}$ of nitrogen and $1 \mathrm{t}$ of phosphorus are needed to produce 100 $\mathrm{t}$ of microalgae biomass. The production of these compounds as fertilizers is limited as well as being associated with high energy consumption and resultant $\mathrm{CO}_{2}$ emissions - indeed, to produce $1 \mathrm{~kg}$ of $\mathrm{NH}_{3}$, more than $10 \mathrm{kWh}$ of energy is required. Consequently, using fertilizers as the nutrient source reduces the sustainability of microalgae-based processes (Lardon et al., 2009). On the other hand, nitrogen and phosphorus can be obtained from effluents such as wastewaters. Because of this, microalgae production using wastewater as the nutrient source is a very promising alternative, which offers added environmental advantages (Olguín, 2012; Pittman et al., 2011; Dong et al., 2014). As a result, microalgae can be produced from urban or animal wastewater using freshwater strains, at the same time helping to depurate the wastewater itself (Olguín, 2003; Muñoz and Guieysse, 2006; Godos et al., 2010; Cabanelas et al., 2013). Microalgae production using wastewater, or other contaminated effluents, has additional advantages as microalgae are effective in removing organic matter, heavy metals and xenobiotics as well as inorganic nutrients (Hernández and Olguín, 2002; Olguín, 2003; Muñoz and Guieysse, 2006) thus producing cleaner effluents with high dissolved oxygen concentrations. Moreover, the heavy metal concentrations found in wastewater are many times lower than the toxic levels for most 
microalgae strains (Dong et al., 2014). Finally, wastewater depuration using microalgae consumes $0.52 \mathrm{MJ} / \mathrm{m}^{3}$ compared to a value of $3.6 \mathrm{MJ} / \mathrm{m}^{3}$ when using conventional systems, resulting in both economic and sustainability advantages (personal communication from Aqualia).

Nonetheless, the utilization of wastewater limits biofuel production to freshwater microalgae strains even though using seawater strains is actually the most sustainable way to produce biofuels (Yang et al., 2011). As an alternative, centrate from the anaerobic digestion of activated sludge produced in wastewater treatment plants can be used as the nutrient source to produce marine microalgae. There are two main advantages of using centrate: (i) the nutrient content is much higher than in wastewater, and (ii) the presence of aerobic microorganisms is scarce because they are produced under anaerobic conditions. Inside wastewater treatment plants the centrate is recirculated to depurate it, meaning higher energy consumption and greater cost. Utilizing centrate allows the nitrogen and phosphorus contained within it to be reused and reduces the number of stages required in the wastewater treatment plant, therefore reducing operating costs (Dong et al., 2014).

The centrate obtained from filtering the digestate (produced by anaerobic digestion) is the most concentrated stream of ammonium/phosphorus to be found in wastewater treatment plants. This centrate has already been used as the nutrient source to cultivate different microalgae strains such as Chlorella sp. Chlorella vulgaris, and Nannochloropsis salina (Li et al., 2011; Cabanelas et al., 2013; Dong et al., 2014). Within the centrate, typical ammonia and phosphate concentrations range from $400-800 \mathrm{mg} \cdot \mathrm{l}^{-1}$ and $20-60 \mathrm{mg} \cdot \mathrm{l}^{-1}$, respectively. In addition to the concentration, the N/P ratio is also important because it determines the nutrient, which potentially limits the growth. This ratio should be close to the optimum nitrogen-to-phosphorus stoichiometry encountered in phytoplankton, which has been described as falling within the 8-45 range (Klausmeler et al., 2004). Centrate may also contain certain constituents that inhibit microalgae growth such as urea, organic acids, phenols and pesticides - at high concentrations these might limit the use of such effluents in microalgae production (Kumar et al., 2010). Consequently, research is needed to determine the optimal centrate percentage that can be mixed with seawater to support algae growth for whichever conditions apply. To examine this, a specific study looking at centrate from each 
wastewater treatment plant should be carried out to evaluate its subsequent use as a nutrient source in microalgae production.

The aim of this research is to determine the feasibility of producing $N$. gaditana microalgae using centrate from a real wastewater treatment plant located in Almeria, in which not only the productivity but also the quality of the biomass produced is analysed. To do this, experiments were carried out using Algal culture medium as the standard alongside culture media prepared by adding different centrate percentages to seawater. Mass balances were then performed to determine nutrient yields, and the optical properties of the biomass were analysed to determine the light-use efficiency of the cultures. The quality of the biomass produced was also analysed.

\section{Materials and methods}

\subsection{Microorganism and culture media}

The marine microalgae Eustigmatophyceae Nannochloropsis gaditana Lubián CCMP 527 was selected because of its high growth rate and productivity under outdoor conditions (San Pedro et al., 2014). Culture inoculum was grown under controlled $\mathrm{pH}(8.0)$ and temperature $\left(25.0^{\circ} \mathrm{C}\right)$ conditions in a 0.51 flask, at an irradiance of $150 \mu \mathrm{E} \cdot \mathrm{m}^{-2} \cdot \mathrm{s}^{-1}$, using Algal medium with $8 \mathrm{mM}$ nitrate (Bionova, Santiago, Spain) in seawater (Fabregas et al., 1984). This medium contains $22.4 \mathrm{mg} \cdot 1^{-1}$ of phosphorus and $890 \mathrm{mg} \cdot 1^{-1}$ of $\mathrm{NaHCO}_{3}$, in addition to small amounts of iron, calcium, potassium, copper, etc. For the experiments, the culture media were prepared using natural seawater. The control culture medium was prepared by adding chemicals to natural seawater at standard concentrations corresponding to Algal culture medium. Experimental culture media were prepared by mixing natural seawater with different centrate percentages (10 to $80 \% \mathrm{v} / \mathrm{v})$ taken directly from a real wastewater treatment plant located in Almeria, Spain. The natural seawater was pumped directly from the Mediterranean and filtered through 10, 5 and $1 \mu \mathrm{m}$ pore-size filters prior to use. No additional treatment was applied to the seawater or culture mediums used. Centrate was obtained directly from the bed filter used in the wastewater treatment plant to separate the solids from the digestate liquid fraction, gathered after the anaerobic digestion of activated sludge produced from wastewater treatment. Therefore, this centrate did not contain solids and was rich in ammonia and phosphorus, in addition to other compounds. A complete 
analysis of the centrate used is shown in Table 1 while Table 2 shows a summary of the main compounds within the different culture media used.

\subsection{Photobioreactors and culture conditions}

Experiments were carried out indoors in four polymetil-metacrilate bubble-column photobioreactors $(0.5 \mathrm{~m}$ in height, $0.09 \mathrm{~m}$ in diameter). The columns had a medium inlet as well as a harvest valve, together with a $\mathrm{pH}$ sensor input at the top. Air was bubbled up from the bottom of the column at $0.2 \mathrm{v} / \mathrm{v}$ min to agitate and remove the dissolved oxygen. The temperature was maintained at $20^{\circ} \mathrm{C}$ by controlling the air temperature in the chamber within which the reactors were installed. To keep the $\mathrm{pH}$ within the optimum range (7.807.85), pure $\mathrm{CO}_{2}$ was injected on demand into the air stream at $0.01 \mathrm{v} / \mathrm{v} / \mathrm{min}$. For this, $\mathrm{pH}$ 5330 probes and an R21 pH-controller from Crison were used. The reactors were artificially illuminated using $28 \mathrm{~W}$ high-efficiency fluorescent tubes (Philips Daylight T5). The illumination simulated the circadian cycle and two irradiance levels were assayed (300 and $500 \mu \mathrm{E} / \mathrm{m}^{2} \mathrm{~s}$ ). The irradiance value was experimentally measured as the mean value at 16 different positions; measurements were performed using a spherical SQS-100 Walz GmbH quantum sensor (Effeltrich, Germany).

Growth experiments were performed simultaneously in all reactors, which were inoculated with $10 \%$ of culture volume from the same standard inoculum. Following this, the reactors were operated in batch mode for 6 days, after which time they were operated in semicontinuous mode. Under these conditions, $25 \%$ of culture volume was harvested every day and replaced with fresh culture media. This was carried out using membrane pulse pumps that introduced fresh media into the reactors during the six central hours of daylight, at $0.111 \cdot h^{-1}$. This dilution rate (D) of 0.25 day $^{-1}$ was previously defined as being optimal under these culture conditions using Algal culture medium (Data not shown). Semicontinuous operation was repeated daily until the culture parameters remained constant, which meant for at least three days. In each experiment, the same culture conditions were assayed in two reactors, thus each experimental condition was assayed in duplicate. Measurements of the biomass concentration as well as the biomass and supernatant characteristics were performed by taking fresh culture from the reactor whereas the biochemical composition was determined from harvested biomass. 
2.3 Biomass concentration, chlorophyll fluorescence, nutrient uptake and quantum

166

167 yield

The dry-weight biomass concentration $(\mathrm{Cb})$ was measured by filtering $50 \mathrm{ml}$ of culture through $0.45 \mu \mathrm{m}$ filters and drying it in an oven at $80^{\circ} \mathrm{C}$ for $24 \mathrm{~h}$. The cell status was checked daily by measuring the chlorophyll fluorescence $(\mathrm{Fv} / \mathrm{Fm})$ ratio with a fluorometer (AquaPen AP 100, Photon System Instruments, The Czech Republic). Nutrient uptake was measured by analysing the nitrogen and phosphorus at the reactor inlet and outlet. The depuration was calculated as the outlet to inlet concentration ratio (Eq. 1). The removal capacity was calculated as the amount of compound removed per time and culture volume unit (Eq. 2).

Nutrient Depuration $=\frac{[\text { Nutrient }]_{\text {inlet }}-[\text { Nutrient }]_{\text {outlet }}}{[\text { Nutrient }]_{\text {inlet }}}$

Eq. 1

Nutrient Removal $=\left([\text { Nutrient }]_{\text {inlet }}-[\text { Nutrient }]_{\text {outlet }}\right) \cdot \mathrm{D}$

Eq. 2

The optical properties of the biomass were measured in a CM-3500d Minolta spectrophotometer-colorimeter with Spectramagic 3.6 Software (Minolta, Germany). For this, a glass cuvette ( $3 \mathrm{~cm}$ wide, $4 \mathrm{~cm}$ high and $1 \mathrm{~cm}$ deep) was filled with $12 \mathrm{ml}$ of culture and colour parameters were immediately obtained, in addition to transmittance at wavelengths ranging from 400 to $700 \mathrm{~nm}$. These measurements were carried out directly on the culture within a few seconds, with no pretreatment or operation, such as centrifugation, extraction, etc. The most popular numerical colour-space system is the $\mathrm{L}^{*} \mathrm{a}^{*} \mathrm{~b}^{*}$ (also referred to as the CIE-LAB system) originally defined by the CIE in 1976. This system defines $\mathrm{L}^{*}$ as a sample's colour lightness measurement, a* measures the red and green components while $b^{*}$ measures the yellow and blue. The extinction coefficient (Ka) was calculated by dividing the average absorption by the biomass concentration $(\mathrm{Cb})$ and light path of the cuvette (p) (Eq. 3).

$$
\mathrm{Ka}=\frac{\mathrm{Abs}}{\mathrm{Cb} \cdot \mathrm{p}}
$$

The average irradiance (in the photosynthetically-active radiation range, PAR) at which cells are exposed inside a culture (Iav), is a function of the irradiance in the absence of cells (Io), the biomass extinction coefficient $(\mathrm{Ka})$, the biomass concentration $(\mathrm{Cb})$ and the light 


$$
\operatorname{Iav}=\frac{\mathrm{Io}}{(\mathrm{Ka} \cdot \mathrm{p} \cdot \mathrm{Cb})}(1-\exp (-\mathrm{Ka} \cdot \mathrm{p} \cdot \mathrm{Cb}))
$$

Quantum yield $\left(\Psi_{\mathrm{E}}\right)$ is defined in microalgal cultures as the amount of biomass generated

path inside the reactor (p). It can be approximated using Equation 4 (Molina-Grima et al., 1997). by the unit of radiation (usually a mole of photons) absorbed by the culture. Since it represents the ratio of biomass generation to absorbed photon flux, it can be calculated by Equation 5 (Molina-Grima et al., 1997), where $\mathrm{Pb}$ stands for the volumetric biomass productivity and Fvol for the photon flux absorbed in the volume unit. The photon flux absorbed through the reactor volume may be obtained from the average irradiance (Iav) on a culture volume basis using Equation 6 (Molina-Grima et al., 1997).

$\Psi_{\mathrm{E}}=\frac{\mathrm{Pb}}{\mathrm{F}_{\mathrm{vol}}}$

Eq. 5

$\mathrm{F}_{\mathrm{vol}}=\mathrm{Iav} \cdot \mathrm{Ka} \cdot \mathrm{Cb}$

Eq. 6

\subsection{Analytical Methods}

For culture medium and supernatant analysis, the standard official methods approved by the Spanish Ministry of Agriculture were used (Ministerio de Agricultura, 1982). Phosphorus was measured by visible spectrophotometry through the phospho-vanado-molybdate complex. Nitrates were quantified using a spectrophotometer between 220 and $275 \mathrm{~nm}$. Ammonium was measured by the Nessler reactive method. With regards to biomass, freeze-dried biomass from each steady state was analysed. Lipids were determined gravimetrically from an extract obtained with chloroform:methanol (2:1) (v/v) (Kochert, 1978). The protein content was determined using the Lowry method. Fatty acids were determined by gas chromatography (Rodríguez-Ruiz et al., 1998).

\section{Results}

The centrate composition used is shown in Table 1. It was observed that, even though the centrate was obtained from wastewater treatment plants, the effluent salinity was high (4.55 $\mathrm{mmhos} / \mathrm{cm}$ ), with an approximate total salt content of $3.6 \mathrm{~g} \cdot \mathrm{l}^{-1}$, much higher than freshwater, which typically contains less than $1.0 \mathrm{~g} \cdot \mathrm{l}^{-1}$ of salt. The main compounds 
contained in this centrate were chloride and bicarbonates, in addition to a high ammonium concentration (up to $615 \mathrm{mg} \cdot \mathrm{l}^{-1}$ ) whereas the nitrate and phosphorus contents were lower, at 29 and $36.0 \mathrm{mg} \cdot 1^{-1}$, respectively. In addition to this, the centrate contained relevant amounts of calcium, potassium, iron, etc., all necessary for microalgae growth. Mixtures prepared solely by adding this centrate to seawater showed a salinity reduction as the centrate percentage increased, because of the lower centrate salinity compared to that of the seawater (Table 2). This is important because a reduction in salinity can be a stress factor in the growth of marine strains such as $N$. gaditana. With respect to the nutrients, by comparing the composition of the Algal culture medium to mixtures that used centrate as the nutrient source, the nitrogen content of the Algal culture medium was observed to be comparable to mixtures obtained using a centrate percentage of $30 \%$; whereas in order to achieve a phosphorus content comparable to that in the Algal culture medium, at least $50 \%$ of centrate needed to be mixed with seawater. Due to the variation in these three parameters (salinity, nitrogen and phosphorus), an optimal centrate percentage in the culture medium cannot be defined without experimental determination. Moreover, because nitrogen is in the form of ammonium rather than nitrate, $N$. gaditana tolerance to high concentrations of ammonium also has to be studied.

Experiments performed in semicontinuous mode at a 0.25 day $^{-1}$ dilution rate demonstrated that centrate can be used as the nutrient source in the production of $N$. gaditana. Steady states were obtained when using centrate percentages between 20 and $70 \%$ (Figure 1A); the biomass productivity being higher the greater the irradiance in the experiments performed. Below $20 \%$ of centrate, the nutrient content of the culture medium was insufficient to support growth at the imposed dilution rate, the culture being washed out even at the higher irradiance. At $80 \%$ of centrate, the ammonium concentration was so high that inhibition reduced the growth rate to below the imposed dilution rate, meaning the culture was also washed out at both irradiances tested. Moreover, above a 50\% centrate level, the ammonium concentration was excessive and biomass productivity was reduced when compared to maximal values obtained at 30 to $50 \%$ centrate levels. The fact that maximal biomass productivity was measured at these centrate percentage levels demonstrated that, under these conditions, the reduction in salinity had no adverse effect on $N$. gaditana biomass productivity. Moreover, the biomass productivity measured within this centrate 
percentage range was equal to that measured using Algal culture medium in seawater at both irradiances tested. The adverse effect of too high a centrate percentage was also observed in the chlorophyll fluorescence measurements (Figure 1B). At centrate percentages higher than $50 \%$, a reduction in chlorophyll fluorescence was clearly observed, dropping from values of 0.65 , measured under normal conditions, to 0.45 , measured when $70 \%$ of centrate was used in the culture medium. No measurements were performed at $10 \%$ and $80 \%$ of centrate because the cultures were washed out. In these cases, no irradiance influence was observed on chlorophyll fluorescence values. To confirm that the adverse behaviour of the culture (when increasing the percentage of centrate) was not due to salinity reduction, an additional set of experiments was performed using Algal medium prepared on seawater diluted with freshwater at different percentages. Results showed that biomass productivity remained constant up to freshwater percentages of $75 \%$; while using only freshwater with no seawater, a notable reduction in biomass productivity occurred (Figure 2A). Moreover, a similar trend was observed for chlorophyll fluorescence measurements, experimental values remaining constant (and higher than 0.6) when using percentages of freshwater in the culture medium up to $75 \%$; and only reducing to 0.4 when using Algal medium prepared in freshwater with no seawater (Figure 2B).

Regarding the culture medium, nitrogen and phosphorus analysis at the reactor inlets and outlets allowed us to calculate the depuration rate (the percentage of compounds removed compared to the inlet value) and removal capacity (the amount of compounds removed per time and culture volume unit) (Figure 3). The nitrogen depuration values that were measured in Algal culture medium were 55\% and $41 \%$ at the higher and lower irradiances tested, respectively; thus indicating that this culture medium had an excess of nitrogen allowing $N$. gaditana growth to be maintained under the culture conditions used (Figure $3 \mathrm{~A})$. In experiments performed using centrate, the results showed that nitrogen depuration was higher, the higher the irradiance, and reduced when the centrate percentage was increased. The maximal value was $80 \%$ when using $20 \%$ of centrate and high irradiance, but it reduced to $23 \%$ when centrate percentages were higher than $50 \%$ whatever the irradiance. The reduction in nitrogen depuration occurring when the centrate percentage was increased in the culture medium is related to a greater excess of nitrogen as well as to the lower biomass productivity achieved at centrate percentages in the culture medium 
higher than 50\%. Regarding phosphorus, the phosphorus depuration values measured using Algal culture medium were $60 \%$ and $44 \%$ at the higher and lower irradiances tested, respectively: indicating that even this culture medium had an excess of phosphorus to maintain $N$. gaditana growth under the culture conditions (Figure 3B). Concerning experiments performed on culture media using centrate, the results showed varying behaviour according to the irradiance. At low irradiance, phosphorus depuration increased with an increase in the centrate percentage up to a value of $50 \%$ - a maximal value of $86 \%$ being measured. Above $50 \%$ of centrate, phosphorus depuration reduced. At high irradiance, phosphorus depuration was high, even at low centrate percentages - with a maximal value of $92 \%$; however, it also reduced when centrate percentages above $50 \%$ were used, dropping to $34 \%$ when a centrate percentage of $70 \%$ was present in the culture medium. The high phosphorus depuration values measured when using low centrate percentages in the culture medium, along with high irradiance, indicate that under these conditions the cultures can be phosphorus limited. It is important to note that European Directive 98/15/EC establishes a water release limit of $10 \mathrm{mg} \cdot \mathrm{l}^{-1}$ for nitrogen and $1 \mathrm{mg} \cdot \mathrm{l}^{-1}$ for phosphorus. In all cases, the outlet nitrogen concentrations present were higher than 10 $\mathrm{mg} \cdot \mathrm{l}^{-1}$, whatever the centrate percentage used in the culture medium; whereas the phosphorus concentration was only lower than $1 \mathrm{mg} \cdot \mathrm{l}^{-1}$ when using high irradiance and centrate percentages below $40 \%$. Regarding the removal capacity, results showed that, for Algal medium, the nitrogen removal capacity was 15.5 and $11.5 \mathrm{mgN}_{\mathrm{N}} \cdot \mathrm{l}^{-1} \cdot \mathrm{day}^{-1}$ at the higher and lower irradiances tested, respectively (Figure 3C). When using centrate, the nitrogen removal capacity was constant and equal to that measured for Algal medium up to centrate percentages of $40 \%$. Above this value, the nitrogen removal capacity increased, especially at centrate percentages higher than $50 \%$. Maximal nitrogen removal of $35 \mathrm{mg}_{\mathrm{N}} \cdot \mathrm{l}^{-1} \cdot$ day $^{-1}$ was measured using $80 \%$ of centrate. Regarding phosphorus, results showed that when using Algal medium, the removal capacity was 3.4 and $2.5 \mathrm{mg}_{\mathrm{P}} \cdot \mathrm{l}^{-1} \cdot \mathrm{day}^{-1}$ at the higher and lower irradiances tested, respectively (Figure 3D). Using centrate, the phosphorus removal capacity increased along with increased centrate percentage in the culture medium, up to $50 \%$ - with a maximal value of $5.1 \mathrm{mg}_{\mathrm{P}} \cdot \mathrm{l}^{-1} \cdot \mathrm{day}^{-1}$ being measured. Above $50 \%$ of centrate, the phosphorus removal capacity reduced. 
The optical properties of the biomass were also measured because these affect light availability inside the culture. To do this, the influence of the culture conditions on the extinction coefficient and the biomass colour were studied (Figure 4). The biomass extinction coefficient produced in Algal culture medium was 0.19 and $0.21 \mathrm{~m}^{2} \cdot \mathrm{g}^{-1}$ when using the lower and higher irradiance levels tested, respectively. These values were similar to those obtained with 30 to $50 \%$ of centrate in the culture medium. Outside of these values, the biomass extinction coefficient was lower, indicating lower biomass light absorption under these conditions. No irradiance influence was observed on the biomass extinction coefficient. Regarding colour measurements, these were performed to indicate changes in the biochemical composition of the biomass. Colour space CIELAB L*a*b* was used; the $a^{*}$ parameter corresponding to variations in colour from magenta to green whereas the $b^{*}$ parameter corresponded to variations in colour from yellow to blue. Results showed a similar trend to that observed in the extinction coefficient. The colour of the samples obtained from centrate were approximate to the colour obtained using Algal culture medium when centrate percentages were between 30 to $50 \%$. Outside of this range, the colour of the samples changed from green to brown with $\mathrm{a}^{*}$ increasing from -7.0 to -4.3 while $b^{*}$ reduced from 57.5 to 45.5 . Colour measurements are a rapid and precise method to determine a sample's "aspect". For this reason they can be used as a control parameter for determining deviation from optimal culture conditions.

The biochemical composition of the biomass was also influenced by the centrate percentage used in the culture medium as well as by the irradiance (Figure 5). Results showed that both the protein and the lipid contents were higher at the higher irradiance, including when Algal culture medium was used. When centrate was used, the protein content reduced along with increased centrate percentage in the culture medium up to $40 \%$, then remained constant. The highest protein content, of $49 \%$ d.wt., was measured when using $20 \%$ of centrate and at the higher irradiance; this was far greater than the $36 \%$ d.wt. measured under the same conditions using Algal culture medium. The biomass protein content agreed with that measured using Algal culture medium at centrate percentages above $40 \%$ for both irradiance levels tested, thus indicating a metabolism change when using low centrate percentages due to phosphorus limitation. With regard to lipids, much smaller variations were observed, the mean lipid content measured at both irradiances were in agreement with 
those measured using Algal culture medium under the same conditions. Mean lipid contents of $24.5 \%$ and $22.0 \%$ d.w.t were measured at 500 and $300 \mu \mathrm{E} / \mathrm{m}^{2} \cdot \mathrm{s}$, respectively. Fatty acids analysis was also performed. As expected, the results showed that the main fatty acids were 20:5n3, 16:1n 7 and 16:0 - however, their profile changed according to the composition of the culture medium used (Figure 6). When using Algal medium, 20:5n3 was 33\%; whereas when using centrate, its percentage increased from a minimum value of $23 \%$ (using $20 \%$ of centrate) to a maximum of $38 \%$ (with $30-40 \%$ of centrate); it reduced again to $25 \%$ when using $70 \%$ of centrate in the culture medium. Contrary behaviour was observed for 16:0 and $16: 1 \mathrm{n} 7$, starting from high values of $32 \%$ and $29 \%$, respectively, when using $20 \%$ of centrate, which reduced to $18 \%$ and $15 \%$, respectively, when the centrate percentage was increased to $30-50 \%$. Then the percentage of $16: 0$ and $16: 1 \mathrm{n} 7$ increased the higher the centrate percentage in the culture medium, up to values of $30 \%$ and $22 \%$, respectively, when using $70 \%$ of centrate. There was no observed influence of irradiance on this behaviour. From these data, it can be concluded that the fatty acid profile is related to biomass productivity, 20:5n3 increased with biomass productivity whereas 16:0 and 16:1n 7 increased when biomass productivity fell.

\section{Discussion}

The use of marine strains has been reported as the most sustainable way to produce biofuels from microalgae because no freshwater is required. However, the nitrogen and phosphorus content of seawater is too low to support high microalgae biomass productivity. To solve this problem, nitrogen and phosphorus can be added as fertilizers but this strategy increases production costs and reduces process sustainability. The alternative is to use residuals from other industries as the nutrient source - of these, the utilization of centrate from wastewater treatment plants is an interesting alternative. Centrate is obtained by separating solids from the anaerobic digestion of activated sludge. It contains high concentrations of nitrogen and phosphorus, the nitrogen mainly in the form of ammonium. To demonstrate if centrate is useful as a nutrient source in microalgae biomass production, it is necessary to define the tolerance limits of the selected strain. Two limits must be defined, the minimum centrate percentage that allows productive cultures to be maintained, and the maximum centrate 
percentage that inhibits growth. Between these two limits, the optimal percentage selection must be defined as a function of biomass productivity and depuration efficiency.

The results reported here demonstrate that centrate from a real wastewater treatment plant can be used to produce $N$. gaditana in seawater. The productivity values obtained were similar to those measured using Algal culture medium (Figure 1), with no stress observed caused by centrate dilution with seawater (Figure 2). It was demonstrated that $N$. gaditana can utilize ammonium as the nitrogen source although concentrations higher than $300 \mathrm{mg} \cdot \mathrm{l}^{-}$ ${ }^{1}$ in the inlet medium (corresponding to $50 \%$ of centrate) cause stress to the cells and reduce productivity; meaning a maximum centrate percentage of $50 \%$ can be used. Ammonium has been reported as toxic for microalgae strains when above $100 \mathrm{mg} \cdot \mathrm{l}^{-1}$ (Collos and Harrison, 2014). For instance, C. sorokiniana was completely inhibited at an ammonium

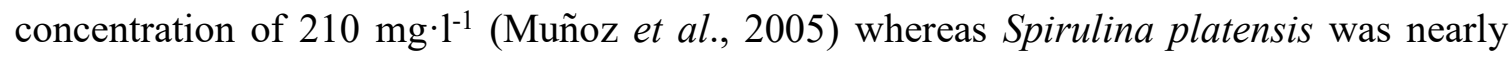
completely inhibited at $150 \mathrm{mg} \cdot \mathrm{l}^{-1}$ (Ogbonna et al., 2000). Chlorella sorokiniana presented similar growth to the artificial medium in 4 to 8 -times-diluted pig slurry, whilst severe biodegradation process inhibition was recorded in undiluted and twice-diluted wastewater (González et al., 2008). Using N. Salina, it was demonstrated that nitrogen can be supplied by adding up to $75 \%$ of centrate to a culture medium; above this value, productivity decreases (Dong et al., 2014). Conversely, if the centrate percentage is lower than $20 \%$, the culture is nutrient limited, and productivity is reduced. The limiting nutrient is not nitrogen, as might be expected, but phosphorus, as observed in the nutrient removal results. The N/P centrate ratio is 13.3 , in the $8-45$ ratio range encountered in phytoplankton (Klausmeler et al., 2004). It has been reported that this range can be modified depending on the culture conditions and the species involved, a factor which determines the most suitable species under different conditions (Klausmeler et al., 2004). Although the centrate composition can change according to the particular wastewater treatment plant's operating conditions, no great variations in the nitrogen/phosphorus ratio are expected, meaning that the centrate percentage range that can be incorporated into the culture medium is defined as being between $30 \%$ and $50 \%$. Given that $30 \%$ of centrate in the culture medium allows one to maintain high productivity (Figure 1) along with higher depuration efficiency (Figure 3), compared to using $50 \%$ of centrate, the former percentage is recommended. 
Biomass production is accomplished by taking up nutrients from the culture medium, the depuration ranging from 80 to $20 \%$ and from 92 to $34 \%$ for phosphorus and nitrogen, respectively. Similarly high depuration rates have also been reported with freshwater microalgae (Craggs et al., 1997; Sydney et al., 2011). With settled domestic sewage and secondary-treated domestic effluent, supplemented with settled swine wastewater, the nitrogen depuration was in the $92-95 \%$ range although the phosphate depuration was lower, at approximately $62-80 \%$ (Wang et al., 2010). However, as depuration is a function of the net concentration supplied, then removal capacity is a more adequate parameter to compare different strains/systems. Data here reported demonstrate that the nitrogen removal capacity using Algal medium (hence the use of nitrate as the nitrogen source) was equal to that measured using centrate. Accordingly, ammonium was used as the nitrogen source when centrate levels below 50\% were used. Under these conditions, the cultures were phosphorus limited, the biomass productivity and the phosphorus removal capacity increased when increasing the centrate percentage in the culture medium up to $50 \%$. Above this value, biomass productivity reduced because of ammonium inhibition and, consequently, the phosphorus removal capacity reduced. Nonetheless, nitrogen removal still increased, indicating there was a relevant contribution from ammonium stripping when operating at such high ammonium concentrations - in spite of the $\mathrm{pH}$ being controlled at 8.0. The maximal nitrogen and phosphorus removal capacity values were $35 \mathrm{mg}_{\mathrm{N}} \cdot \mathrm{l}^{-1}$. day $^{-1}$ and $5.7 \mathrm{mg}_{\mathrm{P}} \cdot \mathrm{l}^{-1} \cdot$ day $^{-1}$, respectively. Using C. Vulgaris, a maximal removal capacity of 9.8 $\mathrm{mg}_{\mathrm{N}} \cdot \mathrm{l}^{-1} \cdot \mathrm{day}^{-1}$ and $3.0 \mathrm{mg}_{\mathrm{P}} \cdot \mathrm{l}^{-1} \cdot \mathrm{day}^{-1}$ were reported using centrate (Cabanelas et al., 2013). On the other hand, nitrogen removal of $8.5 \mathrm{mg}_{\mathrm{N}} \mathrm{l}^{-1} \cdot \mathrm{day}^{-1}$ was reported for Chlorella cultures using ten-fold diluted centrate; this value increasing to $22.7 \mathrm{mg}_{\mathrm{N}} \mathrm{l}^{-1}$. day $^{-1}$ under optimal conditions (Marcilhac et al., 2014). A similar trend was reported for pig manure, with nitrogen removal ranging from 0.5 to $12 \mathrm{mg}_{\mathrm{N}} \mathrm{l}^{-1} \cdot \mathrm{day}^{-1}$ (Sevrin-Reyssac, 1998).

The most intensive parameter for the design and operation of any bioprocess is the coefficient yield. This is the amount of biomass produced per mass unit of nutrient removed from the culture medium. In our study, this parameter was calculated (Figure 7) using biomass productivity values and nutrient concentrations (nitrogen and phosphorus) entering and leaving the reactor. It can be observed that the nitrogen coefficient yield when using Algal culture medium was equal to the expected value of $20 \mathrm{~g}_{\mathrm{b}} \cdot \mathrm{g}_{\mathrm{N}}{ }^{-1}$, which correspond to a 
nitrogen content in the biomass of 5\%d.wt. Using centrate, the same value was obtained when the centrate percentage was in the optimal value range for maximizing biomass productivity, namely from $30 \%$ to $50 \%$. However, outside this range, the nitrogen coefficient yield reduced, so less biomass was produced with the same amount of nitrogen removed from the culture. With respect to phosphorus, the coefficient yield measured using Algal culture medium was in the $90 \mathrm{~g}_{\mathrm{b}} \cdot \mathrm{g}_{\mathrm{P}}{ }^{-1}$ range. However, using centrate, the coefficient yield varied significantly from 150 to $20 \mathrm{~g}_{\mathrm{b}} \cdot \mathrm{g}_{\mathrm{P}}{ }^{-1}$ when the centrate percentage in the culture medium was modified. The optimal phosphorus coefficient yield value was obtained at the optimal centrate percentage in the culture medium - previously defined at $30 \%$, meaning 125 and $150 \mathrm{~g}_{\mathrm{b}} \cdot \mathrm{g}_{\mathrm{P}}{ }^{-1}$ for the lower and higher irradiances tested, respectively. These values correspond to the expected approximate biomass composition, containing 5\%d.wt. of nitrogen and 1\%d.wt. of phosphorus. Reported values for Nannochloropsis salina were 20 $\mathrm{g}_{\mathrm{b}} \cdot \mathrm{g}_{\mathrm{N}}{ }^{-1}$ and $143 \mathrm{~g}_{\mathrm{b}} \cdot \mathrm{g}_{\mathrm{P}}^{-1}$ (Dong et al., 2014), whereas for Chlorella vulgaris values of 20 $\mathrm{g}_{\mathrm{b}} \cdot \mathrm{g}_{\mathrm{N}}{ }^{-1}$ and $65 \mathrm{~g}_{\mathrm{b}} \cdot \mathrm{g}_{\mathrm{P}}{ }^{-1}$ (Cabanelas et al., 2013) were reported; centrate was also used as the culture medium in this case. Using secondary-treated wastewater for the production of Muriellopsis sp., it was observed that the nitrogen and phosphorus coefficient yields approached $20 \mathrm{~g}_{\mathrm{b}} \cdot \mathrm{g}_{\mathrm{N}}{ }^{-1}$ and $100 \mathrm{~g}_{\mathrm{b}} \cdot \mathrm{g}_{\mathrm{P}}^{-1}$, respectively, when operating under nutrientsufficient conditions, whereas under severe nitrogen conditions, they decreased to $10 \mathrm{~g}_{\mathrm{b}} \cdot \mathrm{g}_{\mathrm{N}}^{-}$ ${ }^{1}$ and $6 \mathrm{~g}_{\mathrm{b}} \cdot \mathrm{g}_{\mathrm{P}}{ }^{-1}$ (Gómez et al., 2012). Values of $15 \mathrm{~g}_{\mathrm{b}} \cdot \mathrm{g}_{\mathrm{N}}{ }^{-1}$ and $14 \mathrm{~g}_{\mathrm{b}} \cdot \mathrm{g}_{\mathrm{P}}{ }^{-1}$ were reported using C. vulgaris and artificial culture mediums with up to $400 \mathrm{mg} \cdot 1^{-1}$ of $\mathrm{N}^{-\mathrm{NH}_{4}}{ }^{+}$(Aslan and Kapdan, 2006). Large variations exist in the reported coefficient yield values due to different strains and culture conditions being used, but also due to different phenomena taking place in each one.

The culture medium composition also influenced the optical properties of the biomass and, consequently, the average irradiance inside the culture and the quantum yield. It is important to study these variables because, in addition to nutrients, light-use efficiency must be maximized in whichever microalgae production system used. Analysis of the extinction coefficient and the biomass colour demonstrated that, outside the optimal centrate range in the culture medium, the extinction coefficient diminished meaning more light had to be made available to the cells. Moreover, the light quality inside the reactor was also altered when the centrate percentage was modified because the biomass colour changes 
from green to brown when the centrate percentage in the culture medium is outside the optimal range. In terms of light availability, results showed that within the optimal centrate percentage range in the culture medium, light availability inside the culture was the lowest, with values of $25-30 \mu \mathrm{E} \cdot \mathrm{m}^{-2} \cdot \mathrm{s}^{-1}$, and equal to those when using Algal culture medium (Figure 8A). Outside this optimal range, light availability increased but biomass productivity decreased, thus indicating that cells were not capable of utilising this increased light availability. This is because, at $20 \%$ of centrate, the culture is phosphorus-limited whereas above $50 \%$, the culture is inhibited by an excess of ammonium. These phenomena were better observed when analysing the quantum yield values obtained (Figure 8B). It was shown that at the optimal centrate range in the culture medium, the quantum yield was maximal, with values up to $1.16 \mathrm{~g} \cdot \mathrm{E}^{-1}$, comparable to the $0.9 \mathrm{~g} \cdot \mathrm{E}^{-1}$ value obtained using the Algal culture medium. However, when using centrate percentages outside the optimal range, the quantum yield reduced to values of 0.4 and $0.3 \mathrm{~g} \cdot \mathrm{E}^{-1}$, thus demonstrating lower light-use efficiency under these conditions. In cultures performed with Muriellopsis sp., the quantum yield reduced from $0.6-0.7 \mathrm{~g} \cdot \mathrm{E}^{-1}$ under no, or low, nitrogen limitation to $0.38 \mathrm{~g} \cdot \mathrm{E}^{-1}$ under severe nitrogen limitation (Gómez et al., 2012), meaning this strain is less energy efficient under these conditions. The quantum yield has been reported as reaching maximum values of $0.65 \mathrm{~g} \cdot \mathrm{E}^{-1}$ when culturing Isochrysis galbana at low light under optimal conditions (Molina-Grima et al., 1997), reducing to $0.1 \mathrm{~g} \cdot \mathrm{E}^{-1}$ under high light conditions - to the point of causing photoinhibition. Values reported here were higher, indicating this strain's greater efficiency in using light and that the cultures were highly photolimited.

With respect to the quality of the biomass produced, results demonstrated that the utilization of centrate as the culture medium in the optimal percentage range had little influence on the biomass's protein and lipid content when compared to values using the Algal culture medium. No lipid enhancement was determined by modifying the centrate percentage in the culture medium, a mean lipid content of $23 \%$ d.wt. being measured. Only an increase in the protein content using low centrate percentages was determined, with maximal values of $50 \%$ d.wt., whereas under optimal production conditions, the mean protein content was $34 \%$ d.wt. Because an increase in protein content is not accomplished by a decrease in the lipid content, it is believed that the carbohydrate content is reduced 
under these conditions although this was not measured. Such behaviour indicates that phosphorus limitation might limit the production of carbohydrates, thus enhancing the accumulation of proteins in the biomass. Whatever the reason, as there is little interest in carbohydrate production, this variation has no great consequence from an application point of view. Variation in the fatty acid profile is more relevant when the centrate percentage is modified in the culture medium. Results demonstrated that the 20:5n3 fatty acid profile was richest when using optimal centrate percentages in the culture medium, concurrent with maximal biomass productivity, thus confirming the role of polyunsaturated fatty acids as structural lipids and, consequently, as primary metabolites in this strain. Conversely, under these optimal growth conditions, the proportion of 16:0 and 16:1n7 reduced, indicating lower storage lipid accumulation. It was previously reported that under nitrogen-limited conditions, the percentage of saturated fatty acids increases with respect to values obtained under nitrogen-saturated conditions (San Pedro et al., 2014). Similarly, it was previously reported (Sukenik et al., 1993) that saturated fatty acids increase when irradiance availability increases; with average irradiance inside the culture increasing under nitrogenlimited conditions. Variation in the fatty acids profile is relevant when producing biodiesel, given that saturated and monounsaturated fatty acids are preferred, and N. gaditana production using centrate does not favour these fatty acids and thus may be a disadvantage for biofuel production under these conditions.

Finally, to demonstrate the existence of phosphorus limitation when centrate is used as the sole nutrient source, an additional set of experiments was carried out using $20 \%$ of centrate as the culture medium $\left(\mathrm{N}-\mathrm{NH}_{4}=95.7 \mathrm{mg} \cdot 1^{-1}, \mathrm{P}-\mathrm{PO}_{4}=7 \mathrm{mg} \cdot 1^{-1}\right)$, but supplying additional $\mathrm{NaH}_{2} \mathrm{PO}_{4}$ to achieve a N/P ratio equal to 5, the same as for Algal medium. Results obtained under these conditions are summarized in Figure 9. It was shown that by supplying additional phosphorus, the productivity increased (even when using only $20 \%$ of centrate with lower biomass productivity than at higher centrate percentages). Biomass productivity measured under these conditions was 0.23 and $0.33 \mathrm{~g} \cdot 1^{-1} \cdot$ day $^{-1}$, approaching that measured using the Algal culture medium $\left(0.27\right.$ and $\left.0.37 \mathrm{~g} \cdot 1^{-1} \cdot \mathrm{day}^{-1}\right)$, at the lower and higher irradiance levels tested, respectively. Moreover, phosphorus removal remained in the $80 \%$ range when using both $20 \%$ of centrate and $20 \%$ of centrate enriched with phosphorus as the culture medium; whereas nitrogen removal greatly increased when supplying additional 
523 phosphorus. Therefore, when using only centrate, nitrogen removal was 46 and $51 \%$ for the

524 lower and higher irradiance levels tested, respectively; whereas by supplying additional 525 phosphorus, the nitrogen removal increased to 79 and $85 \%$ for the same levels tested.

526 In summary, although centrate can be used to produce $N$. gaditana biomass for biofuel 527 production, this needs to be supplemented with additional phosphorus. Ideally, residual 528 phosphorus can be used although this compound is scarce. The utilization of commercial 529 fertilizers rich in phosphorus can only be acceptable for minimizing the supernatant 530 nitrogen content if the phosphorus is released into the environment; otherwise, the 531 utilization of external phosphorus sources reduces both the sustainability and economic 532 viability of the overall biofuel production process.

533

534

535

536

537

538

539

540

541

542

543

544

545

546

547

548

549

550

551

552

\section{Conclusions}

It has been demonstrated that the marine microalgae $N$. gaditana can be produced using centrate as the sole nutrient source. The enrichment of seawater with up to $50 \%$ of centrate allows one to achieve higher biomass productivity, comparable to that obtained using standard Algal culture medium, although the cultures become phosphorus limited. Likewise, the quality of the biomass produced is comparable to that obtained using standard Algal culture medium; although regulations concerning the utilization of centrate as the nutrient source might limit its commercial application in producing biomass. Nonetheless, for biofuel production (or related compounds), these types of extraction regulations are not envisaged, meaning the utilization of centrate to produce microalgae would be a cheap and sustainable method for third-generation biofuel production.

\section{Acknowledgements}

This research was financed by DESERT BIOENERGY (Chile) and CO2ALGAEFIX (LIFE10 ENV/ES/000496) led by ALGAENERGY. We are most grateful to Aqualia S.A. for providing water samples and Estación Experimental Las Palmerillas of Fundación Cajamar for collaborating in this research. This research was supported by the Junta de Andalucía and Plan Andaluz de Investigación (BIO 173). 


\section{References}

Acién FG, Fernández JM, Magán JJ, Molina-Grima E. 2012. Production cost of a real microalgae production plant and strategies to reduce it. Biotechnol Adv. 30(6): 13441353.

Aslan S, Kapdan IK. 2006. Batch kinetics of nitrogen and phosphorus removal from synthetic wastewater by algae. Ecol.Eng. 28(1): 64-70.

Cabanelas ITD, Ruiz J, Arbib Z, Chinalia FA, Garrido-Pérez C, Rogalla F, Nascimento IA, Perales JA. 2013. Comparing the use of different domestic wastewaters for coupling microalgal production and nutrient removal. Bioresour Technol 131:429-436.

Chisti Y. 2007. Biodiesel from microalgae. Biotechnol Adv 25: 294-306.

Collos Y, Harrison PJ. 2014. Acclimation and toxicity of high ammonium concentrations to unicellular algae. Mar Pollut Bull 80:8-23.

Craggs RJ, McAuley PJ, Smith VJ. 1997. Wastewater nutrient removal by marine microalgae grown on a corrugated raceway. Water Res 31: 1701-1707.

Dong B, Ho N, Ogden KL, Arnold RG. 2014. Cultivation of Nannochloropsis salina in municipal wastewater or digester centrate. Ecotoxicol Environ Saf 103:45-53.

Fábregas J, Herrero C, Cabezas B, Abalde J. 1984. Growth of the marine microalga Tetraselmis suecica in batch cultures with different salinities. Aquaculture; 42: 207215.

Godos Id, Vargas VA, Blanco S, González MCG, Soto R, García-Encina PA, Becares E, Muñoz R. 2010. A comparative evaluation of microalgae for the degradation of piggery wastewater under photosynthetic oxygenation. Bioresour Technol 101: 51505158.

Gómez C, Escudero R, Morales MM, Figueroa FL, Fernández-Sevilla JM, Acién FG. 2013. Use of secondary-treated wastewater for the production of Muriellopsis sp. Appl Microbiol Biotechnol 97:2239-2249.

González C, Marciniak J, Villaverde S, García-Encina PA, Muñoz R. 2008. Microalgaebased processes for the biodegradation of pretreated piggery wastewaters. Appl Microbiol Biotechnol 80:891-898.

Hernández E, Olguín EJ. 2002. Biosorption of heavy metals influenced by the chemical composition of Spirulina sp. (Arthrospira) biomass. Environ Technol 23: 1369-1377.

Klausmeler CA, Litchman E, Daufreshna T, Levin SA. 2004. Optimal nitrogen-tophosphorus stoichiometry of phytoplankton. Nature 429: 171-174.

Kochert G. 1978. Handbook of phycological methods. London:Cambridge University Press.

Kumar A, Ergas S, Yuan X, Sahu A, Zhang Q, Dewulf J, Malcata FX, van Langenhove H. 2010. Enhanced $\mathrm{CO}_{2}$ fixation and biofuel production via microalgae: Recent developments and future directions. Trends Biotechnol 28: 371-380.

Lardon L, Hélias A, Sialve B, Steyer JP, Bernard O. 2009. Life-cycle assessment of biodiesel production from microalgae. Environ Sci Technol 43: 6475-6481.

Li Y, Chen Y-, Chen P, Min M, Zhou W, Martinez B, Zhu J, Ruan R. 2011. Characterization of a microalga Chlorella sp. well adapted to highly concentrated municipal wastewater for nutrient removal and biodiesel production. Bioresour Technol 102: 5138-5144. 
Marcilhac C, Sialve B, Pourcher A-, Ziebal C, Bernet N, Béline F. 2014. Digestate color and light intensity affect nutrient removal and competition phenomena in a microalgal-bacterial ecosystem. Water Res 64:278-287.

Mata TM, Martins AA, Caetano NS. 2010. Microalgae for biodiesel production and other applications: A review. Renew Sust Energ Rev 14:217-232.

Ministerio de Agricultura. 1982. Métodos oficiales de análisis: suelos y aguas. Ed. Ministerio de Agricultura, Madrid, Spain.

Molina-Grima, E. García Camacho, J.A. Sánchez Pérez, F.G. Acién Fernández, J.M. Fernández Sevilla. 1997. Evaluation of photosynthetic efficiency in microalgal cultures using averaged irradiance, Enz Microbial Technol, 21(5): 375-381

Molina-Grima, E., Acién, F.G., Medina, A.R. 2003. Downstream Processing of Cell-Mass and Products. In Handbook of Microalgal Culture, Blackwell Publishing Ltd, pp. 215-252.

Muñoz R, Jacinto M, Guieysse B, Mattiasson B. 2005. Combined carbon and nitrogen removal from acetonitrile using algal-bacterial bioreactors. Applied Microbiology and Biotechnology 67:699-707.

Muñoz R, Guieysse B. 2006. Algal-bacterial processes for the treatment of hazardous contaminants: A review. Water Res 40: 2799-2815.

Norsker NH, Barbosa MJ, Vermuë MH, Wijffels RH. 2011. Microalgal production: A close look at the economics. Biotechnol Adv 29(1): 24-27.

Olguín EJ, Galicia S, Mercado G, Pérez T. 2003. Annual productivity of Spirulina (Arthrospira) and nutrient removal in a pig wastewater recycling process under tropical conditions. J Appl Phycol 15: 249-257.

Olguín EJ. 2003. Phycoremediation: Key issues for cost-effective nutrient removal processes. Biotechnol Adv 22: 81-91.

Olguín EJ. 2012. Dual purpose microalgae-bacteria-based systems that treat wastewater and produce biodiesel and chemical products within a Biorefinery. Biotechnol Adv 30: 1031-1046.

Pittman JK, Dean AP, Osundeko O. 2011. The potential of sustainable algal biofuel production using wastewater resources. Bioresour Technol 102: 17-25.

Rodríguez-Ruiz J, Belarbi E, García J, López D. 1998. Rapid simultaneous lipid extraction and transesterification for fatty acid analyses. Biotechnol Tech 12: 689-691.

Rosenberg JN, Oyler GA, Wilkinson L, Betenbaugh MJ. 2008. A green light for engineered algae: redirecting metabolism to fuel a biotechnology revolution. Curr Opin Biotechnol 19: 430-436.

San Pedro A, González-López CV, Acién FG, Molina-Grima E. 2014. Outdoor pilot-scale production of Nannochloropsis gaditana: influence of culture parameters and lipid production rates in tubular photobioreactors. Bioresour Technol http://dx.doi.org/10.1016/j.biortech.2014.07.052.

Sevrin-Reyssac J. 1998. Biotreatment of swine manure by production of aquatic valuable biomasses. Agric, Ecosyst Environ 68:177-186.

Schenk PM, Thomas-hall SR, Stephens E, Marx UC, Mussgnug JH, Posten C, Kruse O, Hankamer B. 2008. Second generation biofuels: high-efficiency microalgae for biodiesel production. Bioenergy Res 1: 20-43.

Sydney EB, da Silva TE, Tokarski A, Novak AC, de Carvalho JC, Woiciecohwski AL, Larroche C, Soccol CR. 2011. Screening of microalgae with potential for biodiesel 
production and nutrient removal from treated domestic sewage. Appl Energy 88: 3291-3294.

Wang L, Li Y, Chen P, Min M, Chen Y, Zhu J, Ruan RR. 2010. Anaerobic digested dairy manure as a nutrient supplement for cultivation of oil-rich green microalgae Chlorella sp. Bioresour Technol 101: 2623-2628.

Yang J, Xu M, Zhang X, Hu Q, Sommerfeld M, Chen Y. 2011. Life-cycle analysis on biodiesel production from microalgae: Water footprint and nutrients balance. Bioresour Technol 102(1): 159-165. 
652 Table 1: Composition of centrate obtained from a wastewater treatment plant used to 653 prepare culture medium by mixing with seawater at different proportions.

\begin{tabular}{lclc}
\hline $\mathrm{pH}$ & 8.31 & & \\
Conductivity & $4.55 \mathrm{mmhos} / \mathrm{cm} 25^{\circ} \mathrm{C}$ & & \\
\hline Compound & Concentration, $\mathrm{mg} / \mathrm{L}$ & Compound & Concentration, $\mathrm{mg} / \mathrm{L}$ \\
\hline Chloride & 1093.76 & Carbonate & 24.00 \\
Bicarbonate & 646.77 & Magnesium & 19.00 \\
Ammonium & 615.48 & Iron & 0.39 \\
Sodium & 358.00 & Boron & 0.27 \\
Potassium & 102.00 & Sulphate & 0.22 \\
Calcium & 96.00 & Zinc & 0.09 \\
Phosphorus & 36.02 & Copper & 0.03 \\
Nitrate & 28.94 & Manganese & 0.02 \\
\hline
\end{tabular}

654 
656 Table 2: Salinity, nitrogen (nitrate-ammonium) and phosphorus content of the culture 657 medium used as a function of the centrate percentage added to seawater.

\begin{tabular}{lrrrr}
\hline Centrate, $\%$ & Salinity, $/ \mathrm{L}$ & $\mathrm{N}-N O_{3}, \mathrm{mg} / \mathrm{L}$ & $\mathrm{N}-N H_{4}, \mathrm{mg} / \mathrm{L}$ & $\mathrm{P}_{-} \mathrm{PO}_{4}, \mathrm{mg} / \mathrm{L}$ \\
\hline $0 \%$ (Algal medium) & 25.0 & 112.0 & 0.0 & 22.4 \\
$10 \%$ & 22.9 & 0.7 & 47.9 & 3.6 \\
$20 \%$ & 22.2 & 1.3 & 95.7 & 7.2 \\
$30 \%$ & 19.5 & 2.0 & 143.6 & 10.8 \\
$40 \%$ & 18.5 & 2.6 & 191.5 & 14.4 \\
$50 \%$ & 16.9 & 4.6 & 334.0 & 25.1 \\
$60 \%$ & 13.3 & 5.5 & 400.8 & 30.2 \\
$70 \%$ & 11.0 & 6.4 & 467.5 & 35.2 \\
$80 \%$ & 7.9 & 7.3 & 534.3 & 40.2 \\
\hline
\end{tabular}

658

659 

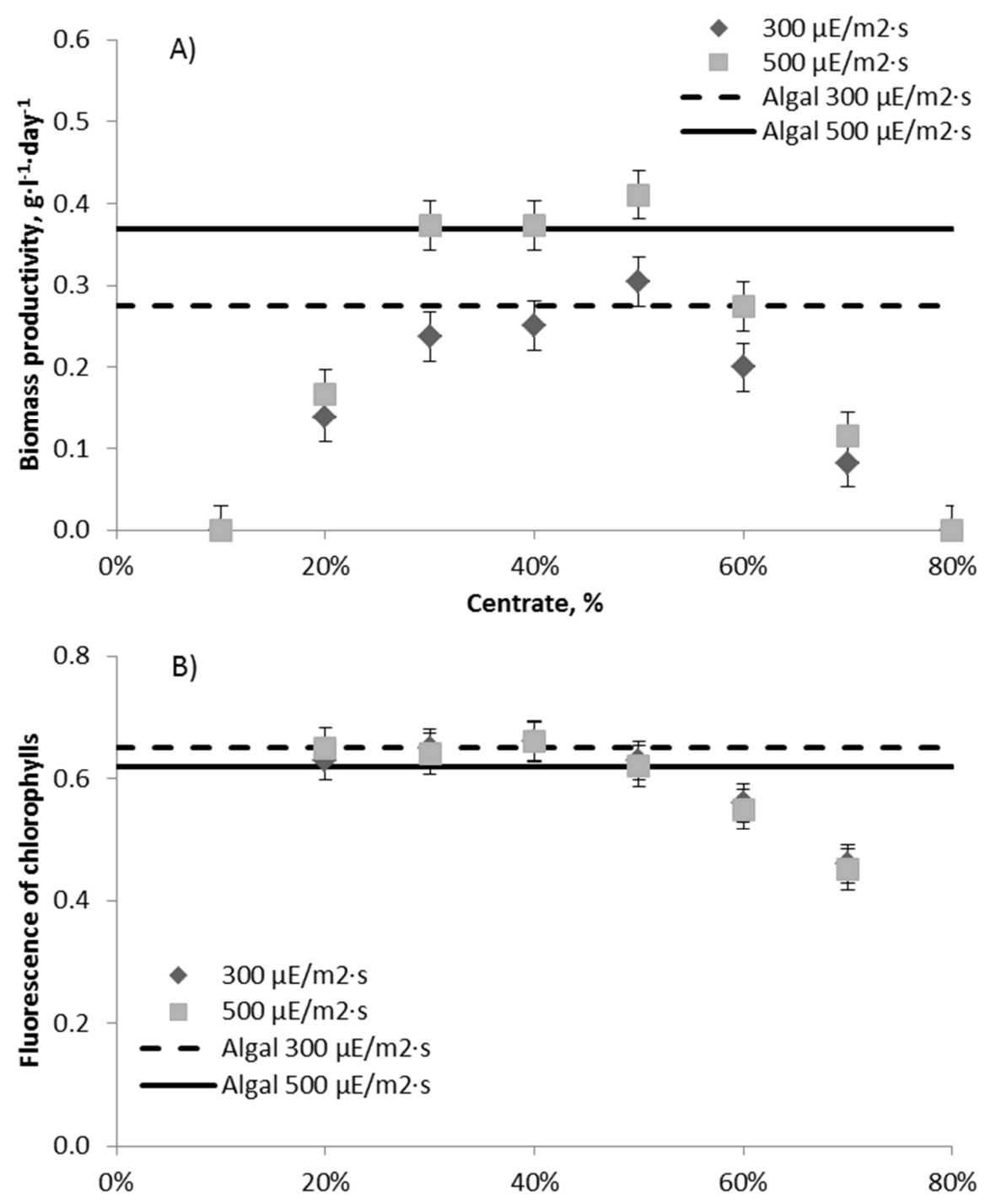

661 Figure 1: Variation of (A) biomass productivity and (B) fluorescence of chlorophylls of $N$.

662 gaditana cultures as a function of the centrate percentage in the culture medium. 663 Experiments performed in semicontinuous mode at $0.251 /$ day, at two irradiance levels. 664 Lines correspond to values obtained using Algal culture medium under the same culture 665 conditions. 

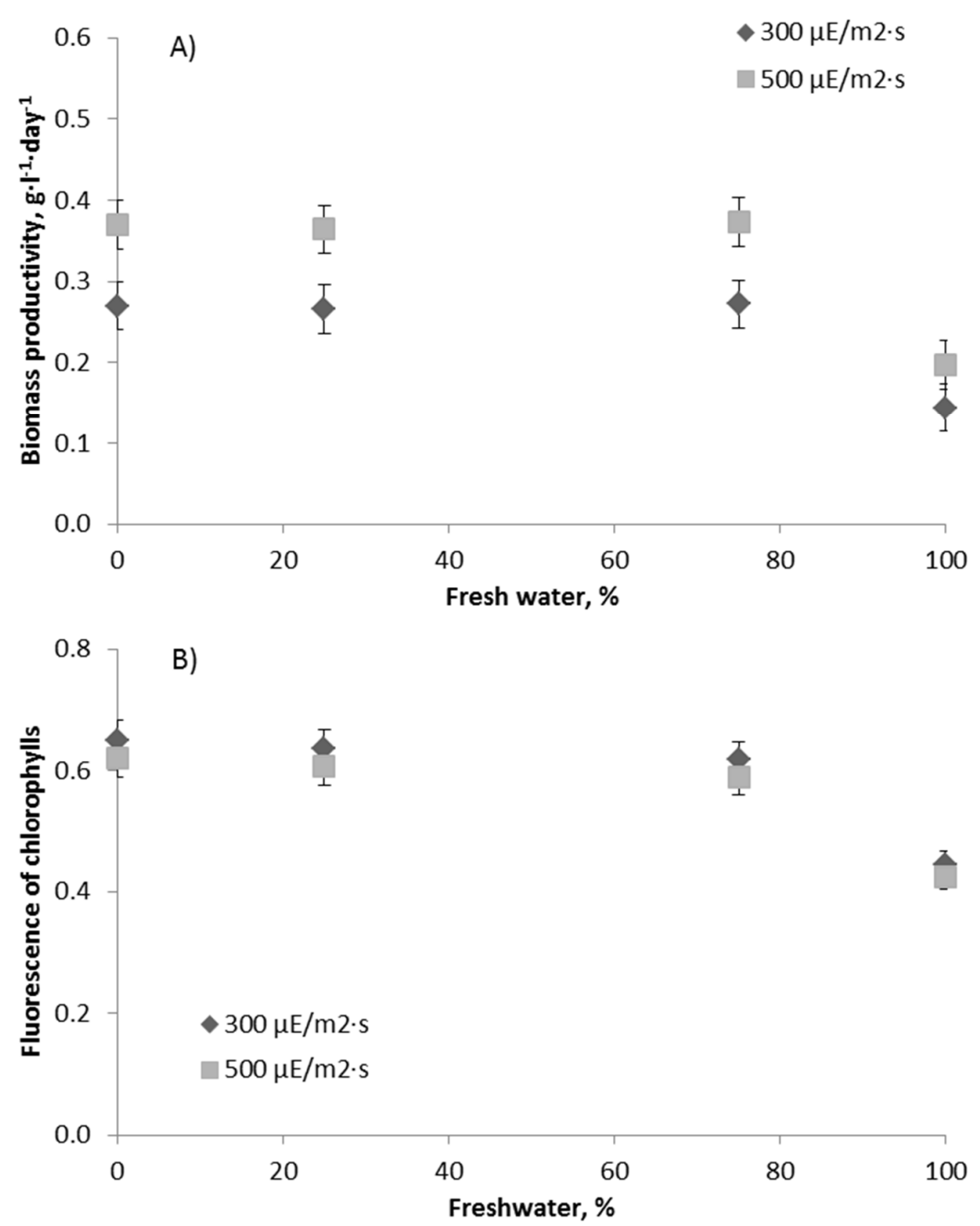

668 Figure 2: Variation of (A) biomass productivity and (B) fluorescence of chlorophylls of $N$. 669 gaditana cultures as a function of the salinity in the culture medium. Experiments 670 performed in semicontinuous mode at $0.251 /$ day, at two irradiance levels, using Algal 671 culture medium under the same culture conditions.

672 

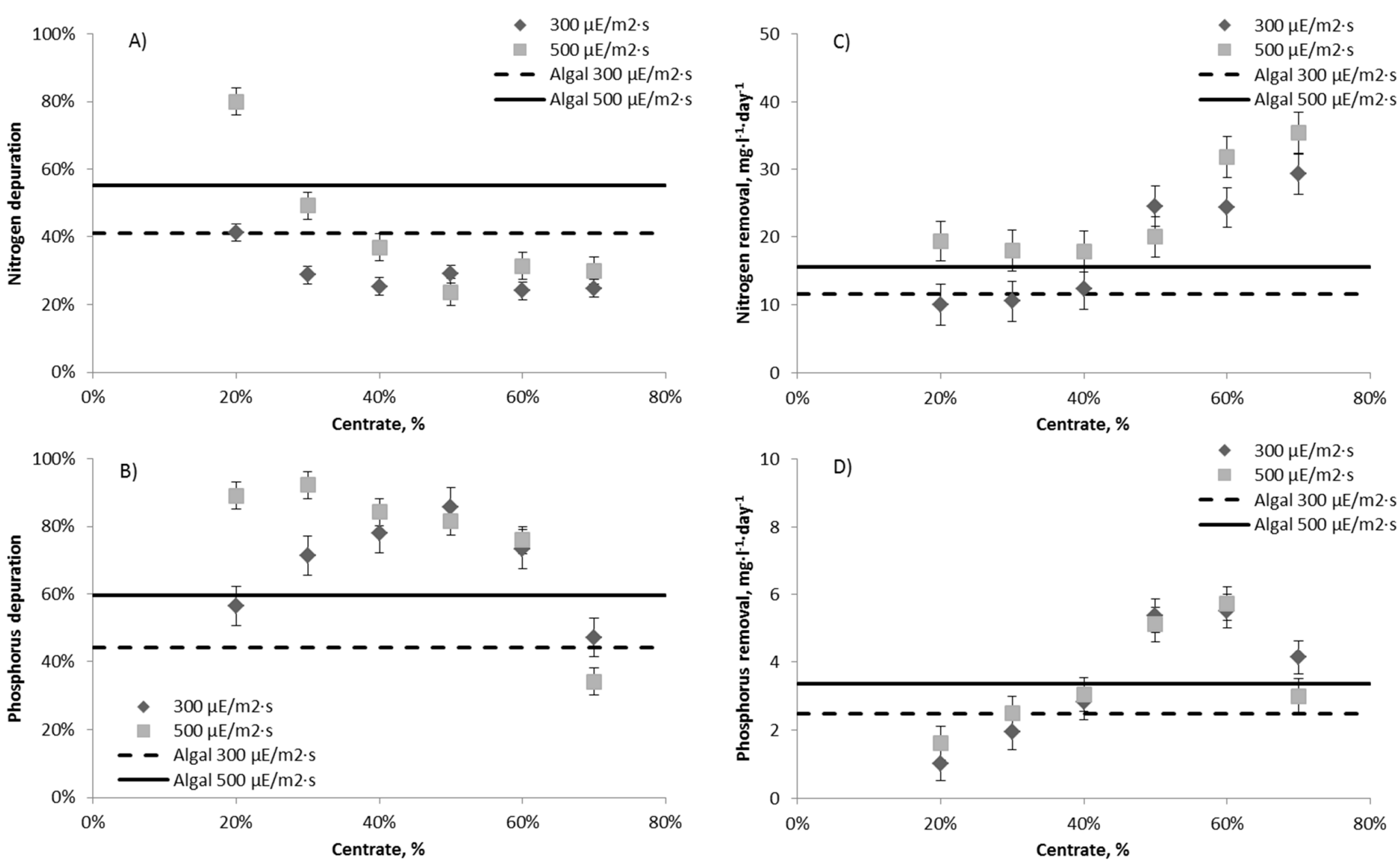

Figure 3: Variation of nitrogen (A) and phosphorus (B) depuration in addition removal capacity of nitrogen (C) and phosphorus (D) of $N$. gaditana cultures as a function of the centrate percentage in the culture medium. Experiments performed in semicontinuous mode at $0.251 /$ day, at two irradiance levels. Lines correspond to values obtained using Algal culture medium under the same culture conditions. 

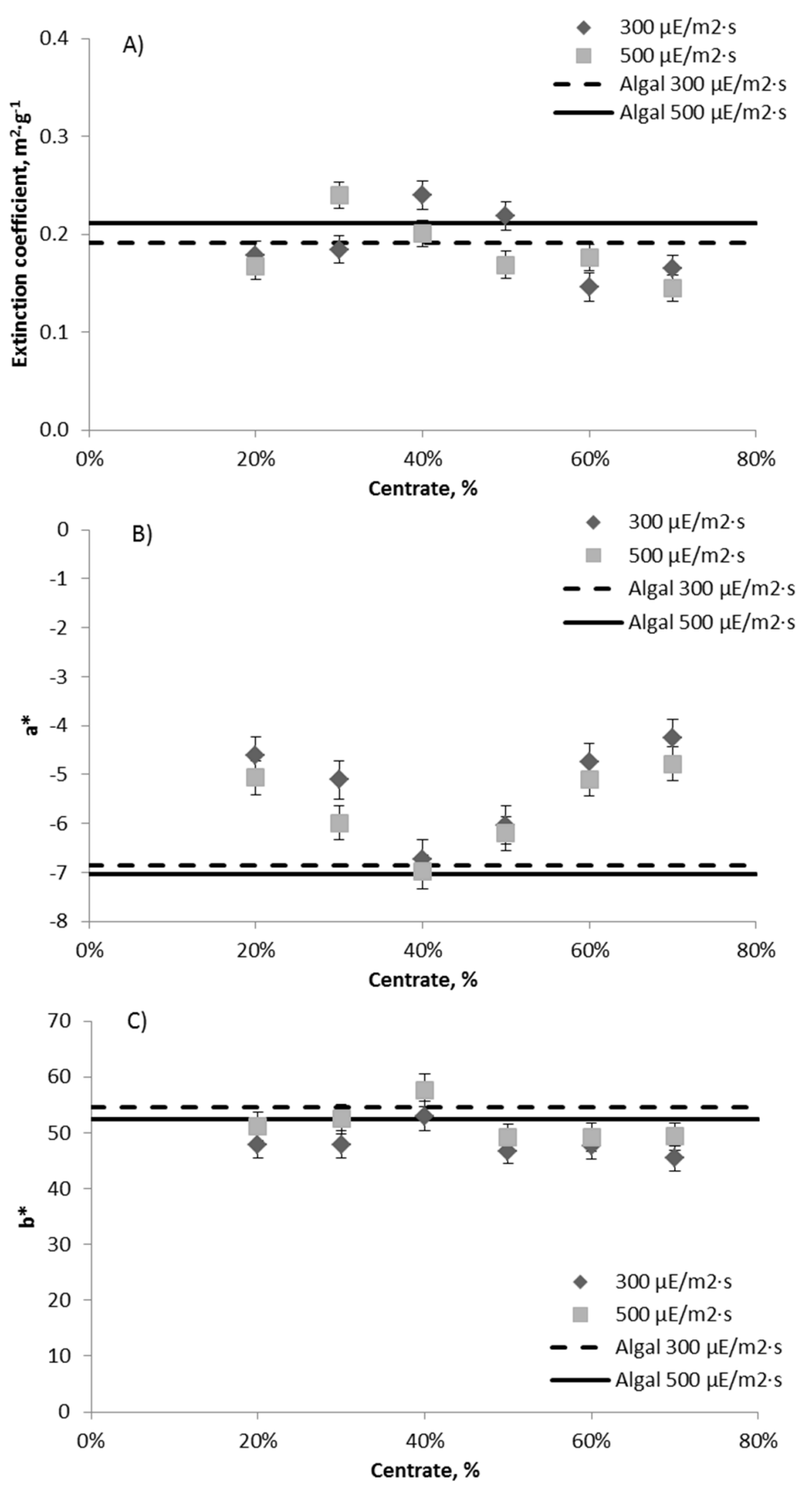

Figure 4: Variation of optical properties of $N$. gaditana cultures as a function of the centrate percentage in the culture medium. A) Extinction coefficient, B) colour coordinate a*, C) 681 Colour coordinate $b^{*}$. Experiments performed in semicontinuous mode at $0.251 /$ day, at 682 two irradiance levels. Lines correspond to values obtained using Algal culture medium 683 under the same culture conditions. 

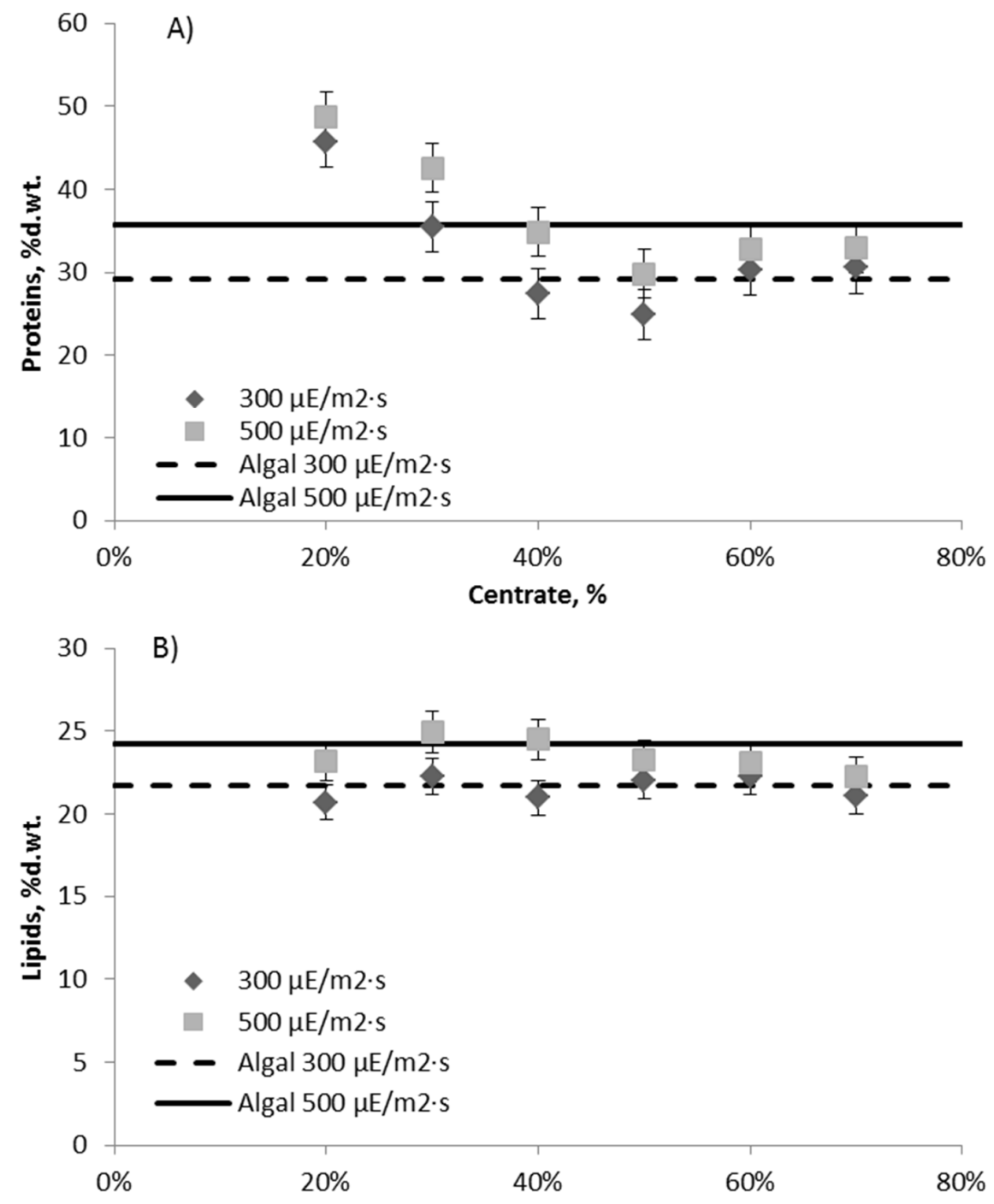

685 Figure 5: Variation of (A) protein and (B) lipid content of $N$. gaditana cultures as a 686 function of the centrate percentage in the culture medium. Experiments performed in 687 semicontinuous mode at $0.251 /$ day, at two irradiance levels. Lines correspond to values 688 obtained using Algal culture medium under the same culture conditions. 


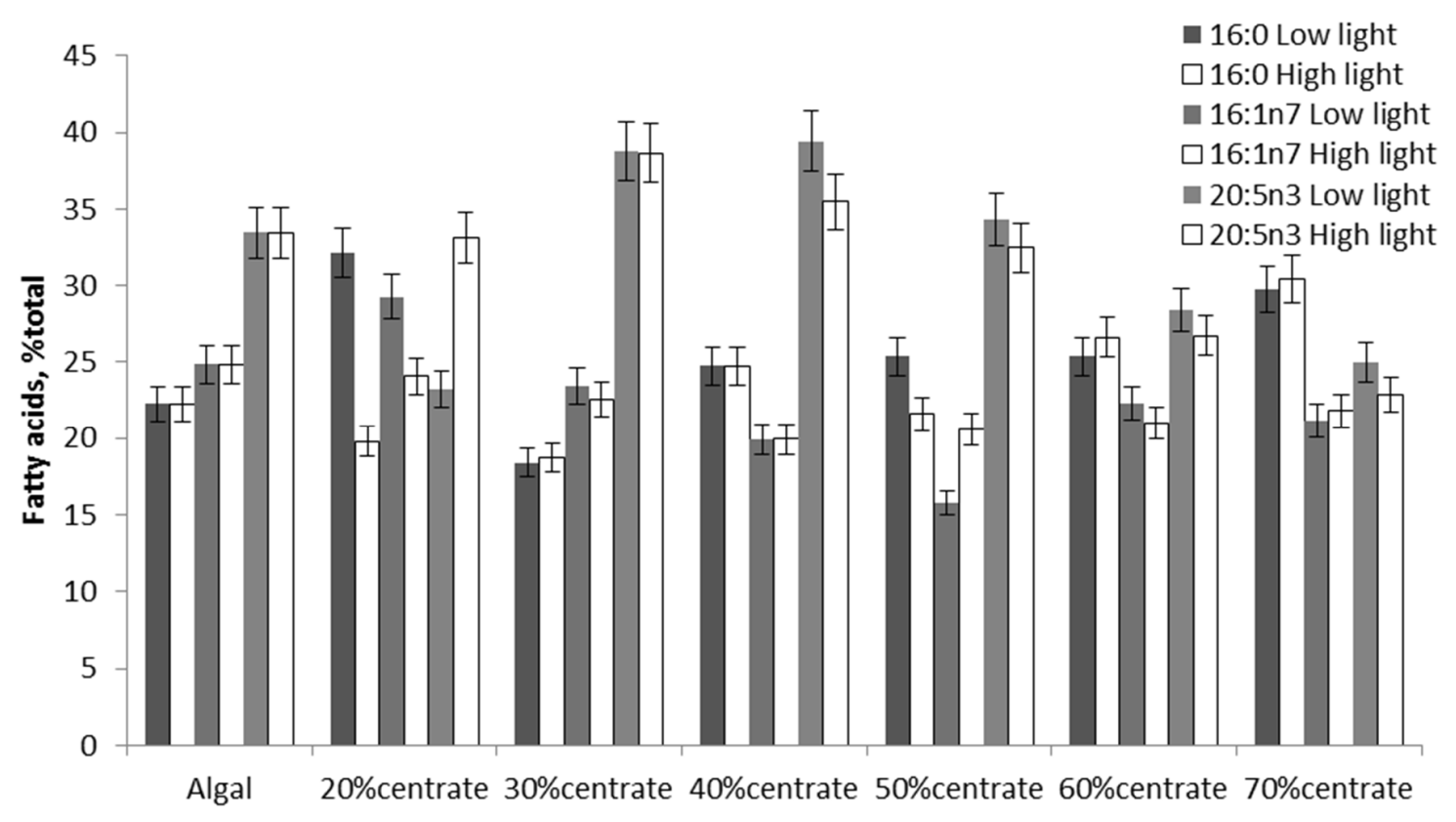

690

691 Figure 6: Variation of fatty acid profile of $N$. gaditana cultures as a function of the centrate 692 percentage in the culture medium. Experiments performed in semicontinuous mode at 0.25 $6931 /$ day, at two irradiance levels: Low light $=300 \mu \mathrm{E} / \mathrm{m}^{2} \mathrm{~s}$ (filled symbols), High light=500 $694 \mu \mathrm{E} / \mathrm{m}^{2} \mathrm{~s}$ (empty symbols). 

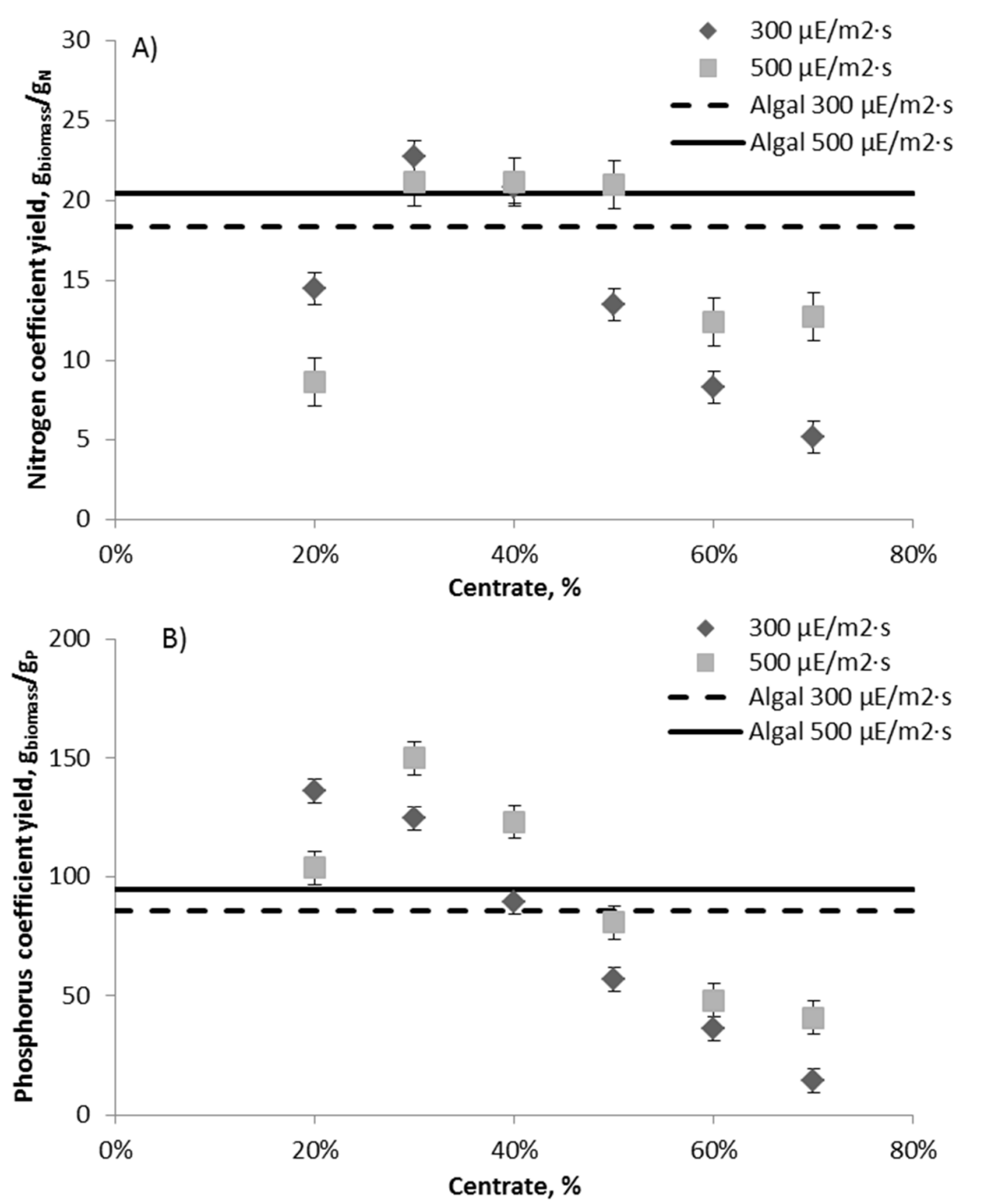

Figure 7: Variation of (A) nitrogen and (B) phosphorus coefficient yields of $N$. gaditana 697 cultures as a function of the centrate percentage in the culture medium. Experiments 698 performed in semicontinuous mode at $0.251 /$ day, at two irradiance levels. Lines 699 correspond to values obtained using Algal culture medium under the same culture 700 conditions. 

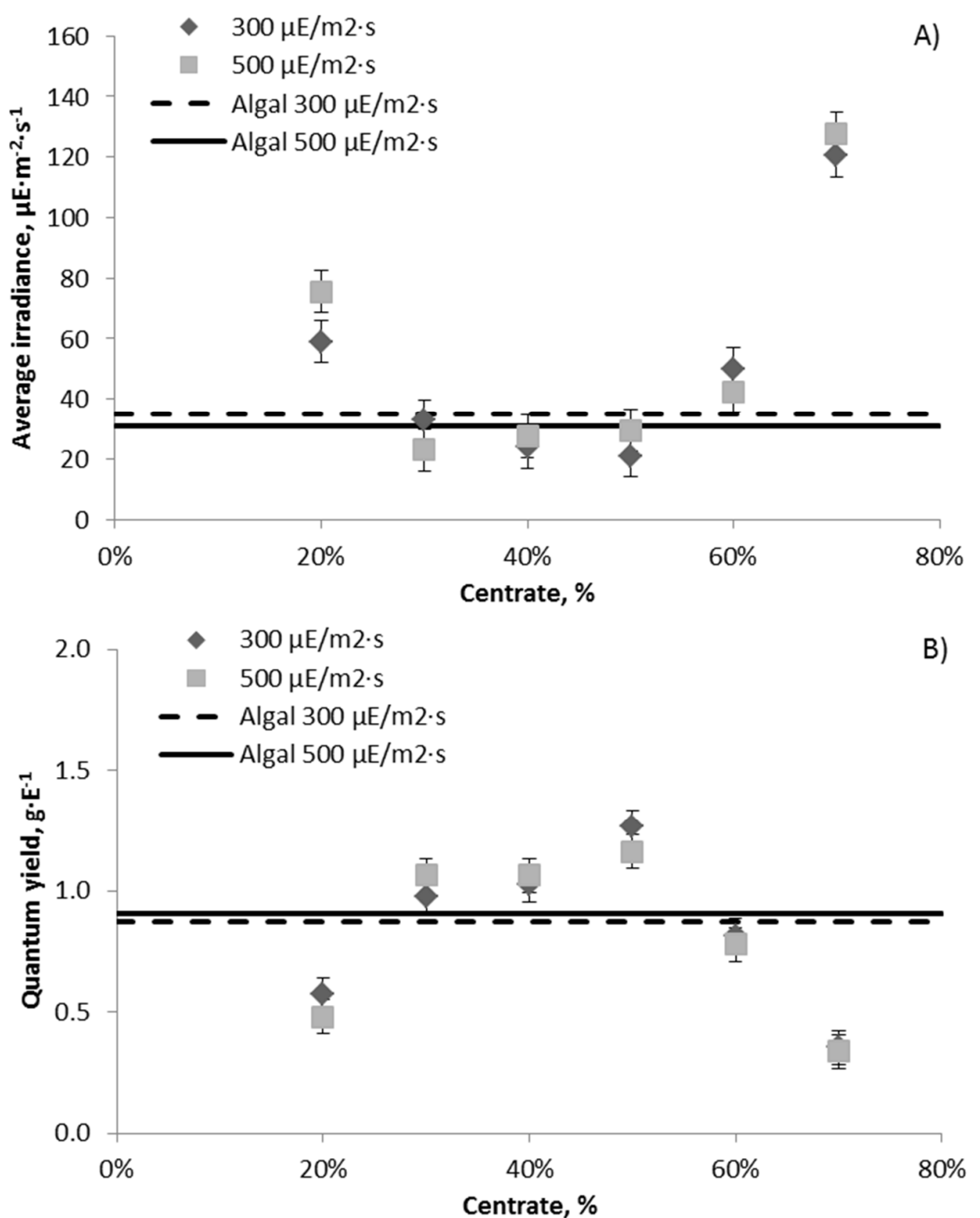

Figure 8: Variation of (A) average irradiance and (B) light-use efficiency of $N$. gaditana cultures as a function of the centrate percentage in the culture medium. Experiments performed in semicontinuous mode at $0.251 /$ day, at two irradiance levels. Lines correspond to values obtained using Algal culture medium under the same culture conditions. 

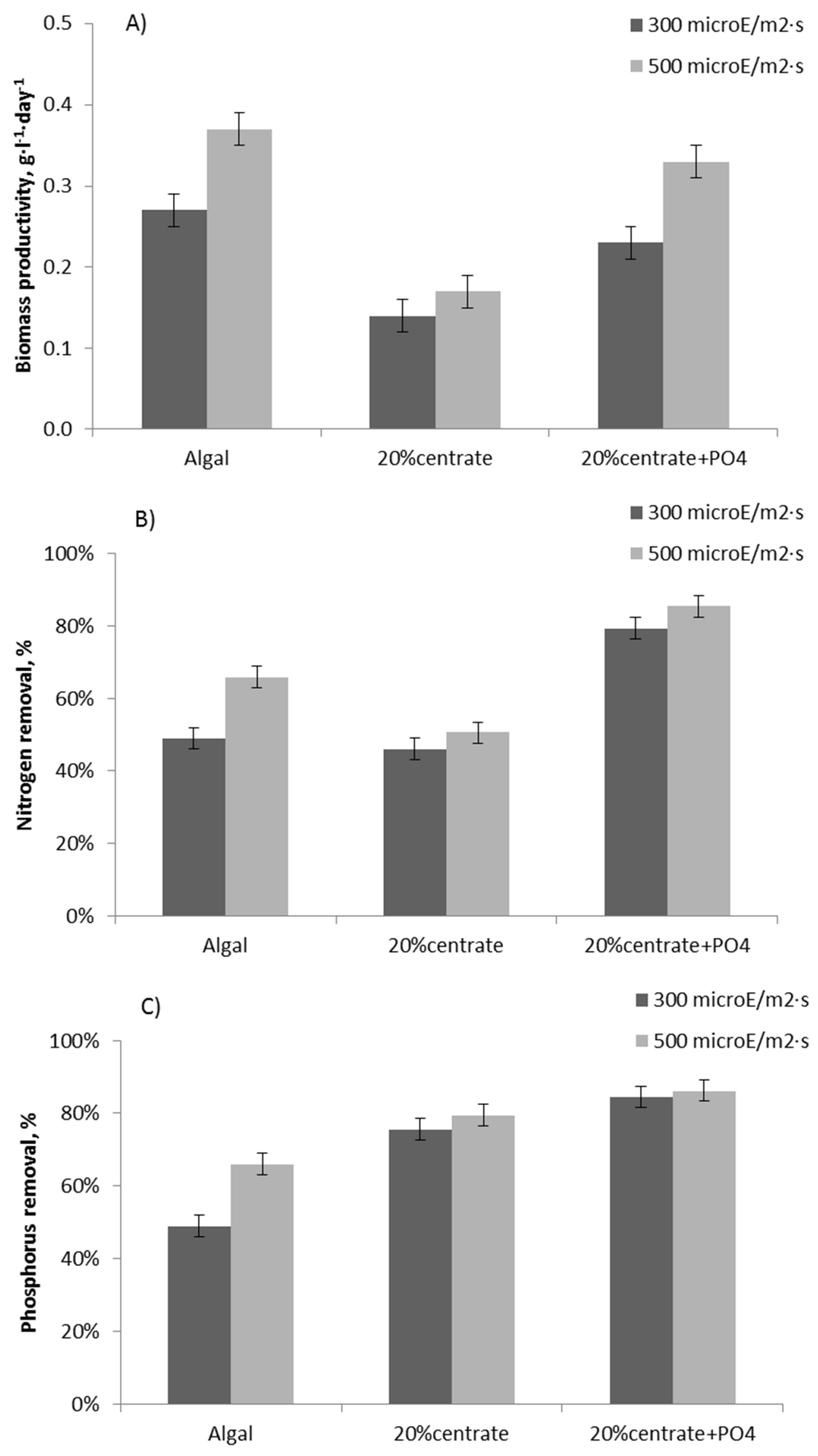

710 Figure 9: Variation of (A) biomass productivity, (B) nitrogen and (C) phosphorus removal 711 with average irradiance as a function of the composition of the culture medium used. 712 Experiments performed in semicontinuous mode at $0.251 /$ day. 